\title{
First observations of the diet of the Pearl Kite (Gampsonyx swainsonii magnus) in southwestern Ecuador
}

\author{
Adrian Orihuela-Torres ${ }^{1,5}$, Jorge Brito ${ }^{2,3} \&$ Juan Manuel Pérez-García ${ }^{4}$ \\ Laboratory of Tropical Ecology and Ecosystem Services, Department of Biological Sciences, Universidad Técnica Particular de Loja, Loja, Ecuador. \\ Department of Biology, Faculty of Sciences, Escuela Politécnica Nacional, Quito, Ecuador. \\ Instituto Nacional de Biodiversidad (INABIO), Quito, Ecuador. \\ 4 Department of Animal Science, Higher Technical School of Agricultural Engineering, University of Lleida, Lleida, Spain. \\ Corresponding author: adrian.orihuela89@gmail.com
}

Received on 21 March 2019. Accepted on 21 July 2019.

\begin{abstract}
We describe the diet of Pearl Kite (Gampsonyx swainsonii magnus) by pellet analysis collected in an active nest in southwest Ecuador in May 2018. Reptiles were the most consumed taxonomic group both in frequency of occurrence $(\mathrm{FO}=46.4 \%)$ and in biomass $(\mathrm{B}=59.8 \%)$, followed by birds $(\mathrm{FO}=33.9 \%$ and $\mathrm{B}=38.3 \%)$ and insects $(\mathrm{FO}=19.6 \%$ and $\mathrm{B}=1.8 \%)$. Our results showed Pearl Kite as a generalist raptor but with a higher consumption of reptiles, which is according with previous studies in other areas where other subspecies inhabit, despite this subspecies showed a higher consumption of birds. Despite the low sample size, this study is interesting as it is the first one on the diet of the Pearl Kite for Ecuador and also for this subspecies. Basic studies on the trophic ecology of Neotropical raptors such as this are needed. For this reason we encourage further studies to fill existing gaps in knowledge and improve effective long-term conservation strategies.
\end{abstract}

KEY-WORDS: pellets, prey, raptor, reptiles, trophic ecology, tropical dry forest.

\section{INTRODUCTION}

Knowing the trophic ecology of a species is important not only to understand the ecology of the species itself, but also to understand the ecology of the community (Lewis et al. 2004). In addition to helping researchers understand trophic niches and how they relate to community structure, studying raptor diets can provide valuable information about prey distribution, abundance, behaviour, and vulnerability (Geng et al. 2009). Neotropical region is one of the areas with the highest diversity of raptors worldwide (Ferguson-Lees \& Christie 2001), however the knowledge about many aspects of the ecology of this group is scarce (Freile et al. 2014, Monsalvo et al. 2018), even for other biological aspects. One of them is the Pearl Kite (Gampsonyx swainsonii), a small raptor that inhabits dry forests and arid regions of Central and South America (van Dort et al. 2010). Three subspecies are recognized, $G$. s. leonae distributed in southwestern El Salvador, south Honduras, west Nicaragua, Costa Rica and Panama, north and east Colombia through Venezuela and Trinidad to Guyana and Suriname, south to northeastern Ecuador and Brazil north of Amazon River; G. s. magnus distributed in west Ecuador and northwestern Peru; G. s. swainsonii distributed in Brazil south of Amazon River to east Peru, north and east Bolivia, Paraguay and N Argentina (Bierregaard-Jr. \& Kirwan 2018). Unlike many other Neotropical raptors, Pearl Kite is favoured by deforestation (Ferguson-Lees \& Christie 2001) and, consequently, it is expanding its range of distribution in recent decades, mainly in Central America, southeast of Brazil and Ecuador (Bierregaard-Jr. \& Kirwan 2018).

Despite being a fairly common raptor in most areas where it lives, it is surprising the lack of detailed studies on its trophic ecology. This raptor is considered a specialist in the capture of small lizards (Ferguson-Lees \& Christie 2001), most of these data had been gathered in field observations or partial diet studies carried out in Central America or northern South America, and are restricted to the subspecies G. s. swainsonii and G. s. leonae (Martínez 1998, Ffrench 2012, Koski et al. 2015, Martínez-Araya \& Gastezzi-Arias 2016, Pineda et al. 2016, Araya-Céspedes \& Carvajal-Sánchez 2017, Herrera \& Acosta-Burgos 2018, Bierregaard-Jr. \& Kirwan 2018). As long as we know, nothing has been published to date about the diet of G. s. magnus.

In this survey we describe the diet of the Pearl Kite 
Gampsonyx s. magnus in southwestern Ecuador, based on the analysis of pellets collected from a single active nest.

\section{METHODS}

On May 2018, we located an active nest of Pearl Kite in the municipality of Zapotillo, province of Loja, southwest

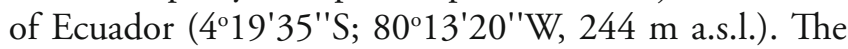
breeding territory was located in a semideciduous dry tropical forest, characterized by discontinuous, natural or induced glades, and the presence of isolated trees (Cueva \& Chalán 2010). The nest was a basket made of loose twigs about $25 \mathrm{~cm}$ in diameter at a height of $4 \mathrm{~m}$ in a Barbasco (Piscidia carthagenensis), and in which there were two fledglings (Fig. 1).

To determine the diet, pellets were collected from the ground under the active nest. Pellets were analysed in the laboratory of the University of Loja (Ecuador). Each pellet was measured with a digital calliper $( \pm 0.01 \mathrm{~mm})$ and weighed with a precision balance Sartorius LA-230P $( \pm 0.01 \mathrm{~g})$. The identification of prey remains found in each pellet followed Orihuela-Torres et al. (2017).

The number of prey was calculated as the number of individuals based on the presence of unique structures, such as elytra of arthropods, jaws of reptiles, feathers and bones of birds, while other parts were not used to avoid double counting (Manning \& Jones 1990). To calculate the biomass of birds not identified, we rely on the size of the bones that were of a medium-sized bird. For each prey and groups consumed, frequency of occurrence (FO) was calculated as the number of individuals of each kind of prey divided by the total number of prey (Formoso et al. 2012, Orihuela-Torres et al. 2017), and biomass consumed (B) multiplying the average body mass of each prey species by the number of total individuals consumed (Orihuela-Torres et al. 2018). Both indexes were shown as a percentage to facilitate comparison. For the calculation of biomass, we used the average mass of each prey species from Instituto Nacional de Biodiversidad (INABIO) collection in Quito, Ecuador (https:// www.inabioecuador.bio/ufl/collections/). The content obtained as remains of birds, insects and reptiles were quite fragmented, therefore it could not be deposited in collections and receive a voucher number. However, this material may be used for teaching purposes and will also be provided to interested researchers.

\section{RESULTS}

A total of 25 pellets were collected and showed the following measures: length (mean $=20.67 \mathrm{~mm}, \mathrm{SD}=$ $4.76 \mathrm{~mm}$, range $=15.83-29.27 \mathrm{~mm})$, width $($ mean $=$ $11.82 \mathrm{~mm}, \mathrm{SD}=3.12 \mathrm{~mm}$, range $=8.5-17.64 \mathrm{~mm})$, mass $($ mean $=0.44 \mathrm{~g}, \mathrm{SD}=0.26 \mathrm{~g}$, range $=0.2-1.2 \mathrm{~g}$ ). We found 56 prey from at least seven species belonging to three different classes: birds ( 2 spp. at least), reptiles (3 spp.), and insects (1 family). Prey mass varied from $1 \mathrm{~g}$ (Carabidae) to $30 \mathrm{~g}$ (Iguana iguana juvenile). Reptiles were

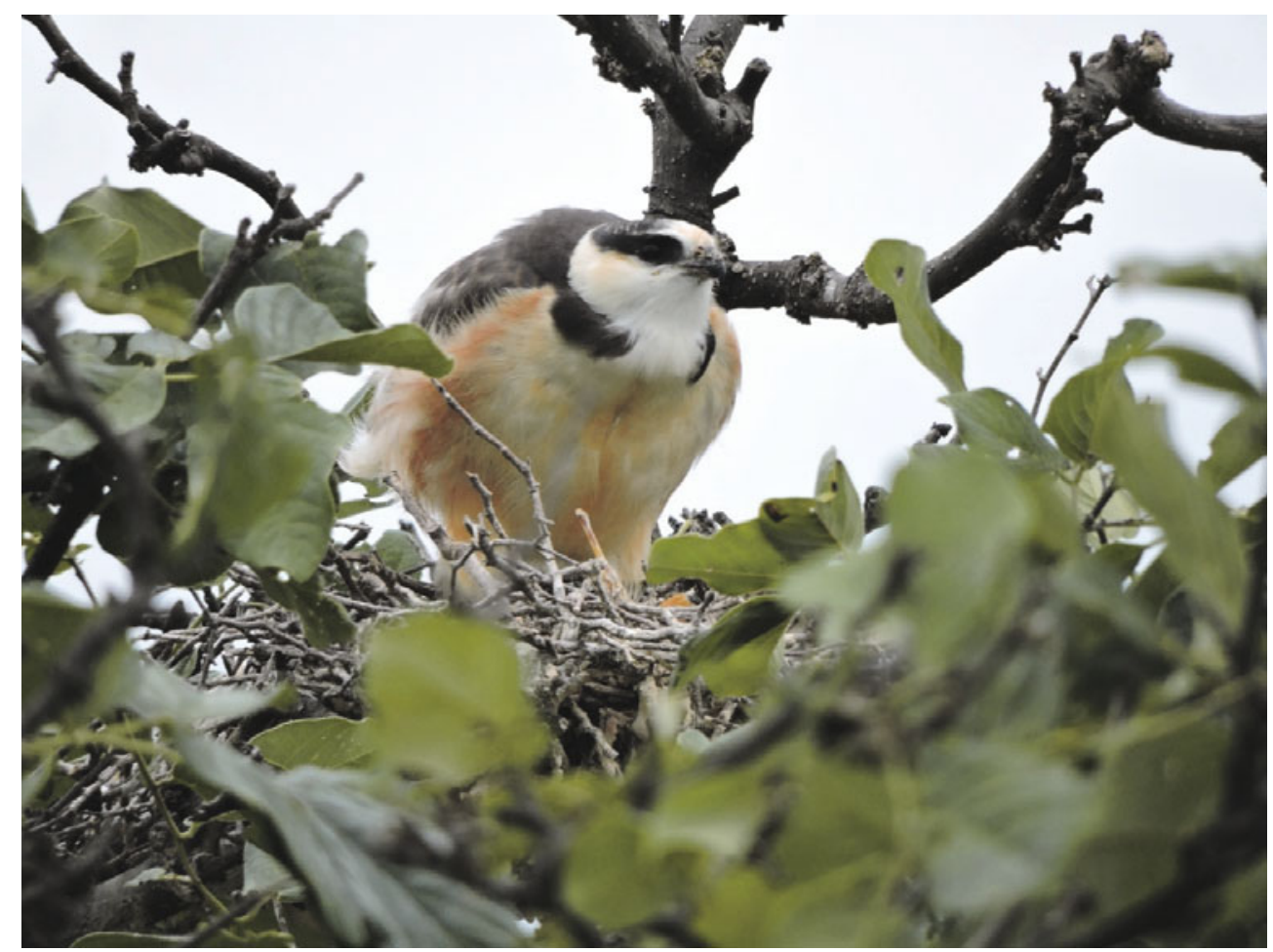

Figure 1. Nest of Pearl Kite (Gampsonyx swainsonii magnus) with one of the two fledglings, in Zapotillo, southwestern Ecuador. 
the main prey both in frequency of occurrence $(46.4 \%)$ and in biomass consumed (59.8\%, Fig. 2). Second in rank were birds (FO: $33.9 \%$ and $\mathrm{B}: 38.3 \%$ ), and then insects (FO: $19.6 \%$, and B: 1.8\%). At the species level, Knobbed Pacific Iguana (Microlophus occipitalis) was the most abundant prey both in frequency of occurrence (39.3\%), as in biomass consumed (47.3\%). Although most birds could not be identified at species level, they appeared in a large percentage of the pellets $(76 \%)$. Carabids also showed a high frequency of occurrence (19.6\%), in 32\% of pellets, however their contribution in biomass was scarce $(1.8 \%)$ (Table 1$)$.

\section{DISCUSSION}

The diet of Pearl Kite in Zapotillo (SW Ecuador) corresponding to the subspecies Gampsonyx s. magnus, was in accordance with previous occasional data recorded for the other two Pearl Kite subspecies, placing this raptors as generalist, but consuming mainly reptiles (Martínez 1998, Koski et al. 2015, Martínez-Araya \& Gastezzi-Arias 2016, Pineda et al. 2016, Araya-Céspedes \& Carvajal-Sánchez 2017, Herrera \& Acosta-Burgos 2018). The consumption of birds in our study seems much more common than previously reported (e.g., Bierregaard-Jr. \& Kirwan 2018). Several hypothesis could explain this results, i.e., plasticity in foraging behaviour and prey selection due to a higher local prey abundance (Morrison et al. 2008), or adaptation of this subspecies to consume more birds than the others subspecies. But due to the small sample size of our study we cannot support statistically any conclusion.

In this sense the composition of the diet would confirm the preference of this raptor for foraging in open habitats where it would find a higher abundance of reptiles such as $M$. occipitalis (Chávez-Villavicencio et al. 2018). Likewise, this statement is supported by the presence of birds related to open habitats and bushes such as the Saffron Finch (Sicalis flaveola) (Ridgely \& Greendfield 2001).

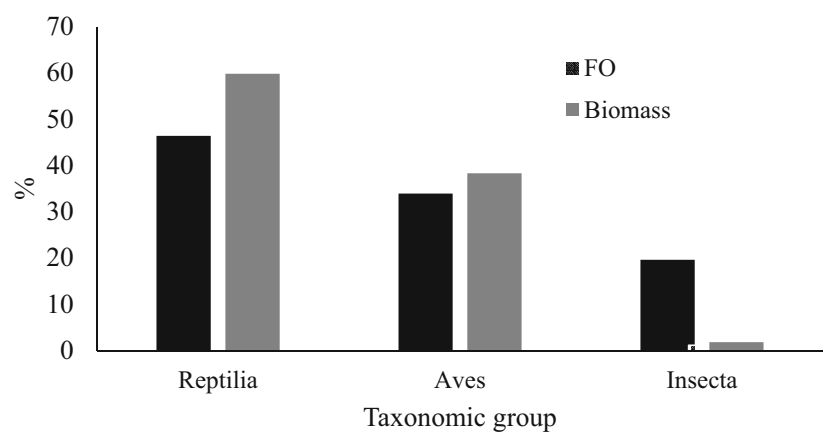

Figure 2. Frequency of occurrence (FO) and biomass consumed (B) in percentage of the diet of Pearl Kite (Gampsonyx swainsonii magnus) in a breeding territory of Zapotillo, southwestern Ecuador.

Table 1. Diet composition of the Pearl Kite (Gampsonyx swainsonii magnus) in a breeding territory of Zapotillo, southwestern Ecuador. The number of individuals consumed of each species is shown ( $n$ ind.), frequency of occurrence (FO) in percentage (\%), the total biomass consumed (Biomass, in g) and the percentage (Biomass, in \%).

\begin{tabular}{|c|c|c|c|c|}
\hline Class/Order/Family/Species & $n$ ind. & FO (\%) & Biomass (g) & Biomass (\%) \\
\hline Reptilia & 26 & 46.4 & 362 & 59.8 \\
\hline \multicolumn{5}{|l|}{ Squamata } \\
\hline \multicolumn{5}{|l|}{ Iguanidae } \\
\hline Microlophus occipitalis & 22 & 39.3 & 286 & 47.3 \\
\hline Iguana iguana (juvenile) & 1 & 1.8 & 30 & 5.0 \\
\hline Polychrus femoralis & 1 & 1.8 & 22 & 3.6 \\
\hline \multicolumn{5}{|l|}{ Phyllodactylidae } \\
\hline Phyllodactylus reissii & 2 & 3.6 & 24 & 4.0 \\
\hline Insecta & 11 & 19.6 & 11 & 1.8 \\
\hline \multicolumn{5}{|l|}{ Coleoptera } \\
\hline Carabidae & 11 & 19.6 & 11 & 1.8 \\
\hline Birds & 19 & 33.9 & 232 & 38.3 \\
\hline \multicolumn{5}{|l|}{ Passeriformes } \\
\hline \multicolumn{5}{|l|}{ Emberizidae } \\
\hline Sicalis flaveola & 2 & 3.6 & 28 & 4.6 \\
\hline Medium-sized birds & 17 & 30.4 & 204 & 33.7 \\
\hline Total & 56 & 100 & 605 & 100 \\
\hline
\end{tabular}


Raptors are very important components in the ecosystems, since they can be used as bioindicators or key species for community monitoring, in addition to providing important ecosystem services (Donázar et al. 2016). Currently there are large gaps in knowledge of basic aspects of raptor ecology in the Neotropics (Buechley et al. 2019) such as the composition of diet, phenology and reproduction, home range or even population sizes. Basic information like this study is necessary to complete these gaps, but since the diet varies depending on factors such as sex, age, habitat and season (Beeston et al. 2005) it is necessary that this knowledge be completed throughout the distribution area, as well as replicated during different seasons and by age classes. By improving our knowledge of the trophic ecology of these magnificent birds at the top of the food chain, we will be able to propose effective long-term conservation strategies.

\section{ACKNOWLEDGEMENTS}

Field work was supported by the SENESCYT project "Spatio-temporal responses of bird and bat communities to altitudinal gradients and disturbance in three ecosystems south of Ecuador" (PIC-13-ETAPA-004). J.M. Pérez-García was supported by a Juan de la Cierva research contract by the Ministry of Economy and Competitiveness (FJCI-2015-25632).

\section{REFERENCES}

Araya-Céspedes O. \& Carvajal-Sánchez J.P. 2017. Ampliación del rango de distribución y depredación sobre reptiles de Gampsonyx swainsonii (Aves: Accipitridae) en la Zona Norte de Costa Rica. Zeledonia 21: 60-62.

Beeston R., Baines D. \& Richardson M. 2005. Seasonal and betweensex differences in the diet of Black Grouse Tetrao tetrix. Bird Study 52: $276-281$.

Bierregaard-Jr. R.O. \& Kirwan G.M. 2018. Pearl Kite (Gampsonyx swainsonii). In: del Hoyo J., Elliott A., Sargatal J., Christie D.A. \& de Juana E. (eds.). Handbook of the birds of the world alive. Barcelona: Lynx Editions. http://www.hbw.com/node/52965 (Accessed on 10 July 2018).

Buechley E.R., Santangeli A., Girardello M., Neate-Clegg M.H., Oleyar D., McClure C.J. \& Şekercioğlu Ç.H. 2019. Global raptor research and conservation priorities: tropical raptors fall prey to knowledge gaps. Diversity and Distributions 25: 856-869.

Chávez-Villavicencio C., Ibáńez-Álvarez Y. \& Charcape-Ravelo J.M. 2018. Selección de hábitat y composición de la dieta de Microlophus occipitalis (Reptilia: Tropiduridae) en Sechura, PiuraPerú. Revista Peruana de Biología 25: 221-228.

Cueva J. \& Chalán L. 2010. Cobertura vegetal y uso actual del suelo de la provincia de Loja. Loja: Amazon Graphics.

Donázar J.A., Cortés-Avizanda A., Fargallo J.A., Margalida A.,
Moleón M., Morales-Reyes Z., Moreno-Opo R., Pérez-García J.M., Sánchez-Zapata J.A., Zuberogoitia I. \& Serrano D. 2016. Roles of raptors in a changing world: from predators to providers of key ecosystem services. Ardeola 63: 181-234.

Ferguson-Lees J. \& Christie D.A. 2001. Raptors of the world. New York: Cristopher Helm.

Ffrench R. 2012. A guide to the birds of Trinidad and Tobago. Ithaca: Cornell University Press.

Formoso A.E., Teta P. \& Cheli G. 2012. Food habits of the Magellanic Horned Owl (Bubo virginianus magellanicus) at southernmost Patagonia, Argentina. Journal of Raptor Research 46: 401-406.

Freile J.F., Greeney H.F. \& Bonaccorso E. 2014. Current Neotropical ornithology: research progress 1996-2011. Condor 116: 84-96.

Geng R., Zhang X., Ou W., Sun H., Lei F., Gao W. \& Wang H. 2009. Diet and prey consumption of breeding Common Kestrel (Falco tinnunculus) in northeast China. Progress in Natural Science 19: 1501-1507.

Herrera N. \& Acosta-Burgos J.C. 2018. Notes on nesting Pearl Kite (Gampsonyx swainsonii) in El Salvador. Spizaetus 26: 13-19.

Koski D.A., de Oliveira G.S., Valadares-Koski A.P. \& Costa H.C. 2015. Predation of Ameivula nativo (Squamata: Teiidae) by Gampsonyx swainsonii (Accipitriformes: Accipitridae) in Espírito Santo, Brazil. Herpetologia Brasileira 4: 100-101.

Lewis S.B., Fuller M.R. \& Titus K. 2004. A comparison of 3 methods for assessing raptor diet during the breeding season. Wildlife Society Bulletin 32: 373-85.

Manning R.W. \& Jones J.K. 1990. Remains of small mammals recovered from Barn Owl pellets from Crosby County, Texas. Texas Journal of Science 42: 311-312.

Martínez C. 1998. Occurrence of reproductive Little Eagle, Gampsonyx swainsonii (Aves: Accipitridae) in São Luís do Maranhão. Ararajuba 6: 58-59.

Martínez-Araya D. \& Gastezzi-Arias P. 2016. Establecimiento del Milano Chico (Gampsonyx swainsonii, Aves: Accipitridae) y observaciones del primer registro de anidación en un área urbanizada del Valle Central, Costa Rica. Brenesia 85-86: 65-68.

Monsalvo J.A.B., Heming N.M. \& Marini M.Â. 2018. Breeding biology of Neotropical Accipitriformes: current knowledge and research priorities. Revista Brasileira de Ornitologia 26: 151-186.

Morrison J.L., Pias K.E., Abrams J., Gottlieb I.G., Deyrup M. \& McMillian M. 2008. Invertebrate diet of breeding and nonbreeding Crested Caracaras (Caracara cheriway) in Florida. Journal of Raptor Research 42: 38-47.

Orihuela-Torres A., Perales P., Rosado D. \& Pérez-García J.M. 2017. Feeding ecology of the Common Kestrel Falco tinnunculus in the south of Alicante (southeast Spain). Revista Catalana d'Ornitologia 33: $10-16$.

Orihuela-Torres A., Ordoñez-Delgado L., Verdezoto-Celi A. \& Brito J. 2018. Diet of the Spectacled Owl (Pulsatrix perspicillata) in Zapotillo, southwestern Ecuador. Revista Brasileira de Ornitologia 26: $52-56$.

Pineda L., de Navas E.M. \& Fernández R.A. 2016. New locations for and first record of nesting Pearl Kite (Gampsonyx swainsonii) in El Salvador. Spizaetus 22: 6-13.

Ridgely R.D. \& Greenfield P.J. 2001. The birds of Ecuador, field guide. New York: Cornell University Press.

van Dort J., Komar O., Juárez-Jovel R.C. \& Espinal M. 2010. First records of Pearl Kite Gampsonyx swainsonii for El Salvador and Honduras. Cotinga 32: 129-130.

Associate Editor: Carla S. Fontana. 